\title{
Integrasi Pembelajaran Ips Dan Ipa Kelas IV Di Madrasah Ibtidaiyah Pembina Pengamalan Agama (MI P2A) Meri Kutasari Purbalingga
}

\author{
Tarsini $^{1}$, Tutuk Ningsih ${ }^{2}$ \\ ${ }^{1}$ Mahasiswa Pascasarjana Pendidikan Guru Madrasah Ibtidaiyah, UIN Prof. UIN Prof. KH. \\ Saifuddin Zuhri \\ ${ }^{2}$ Dosen Pascasarjana Pendidikan Guru Madrasah Ibtidaiyah, UIN Prof. UIN Prof. KH. Saifuddin \\ Zuhri \\ Email: tarsinikdjp@gmail.com ${ }^{1}, \underline{\text { tutuk@iainpurwokerto.ac.id }}{ }^{2}$
}

\begin{abstract}
The integration of Social Science (IPS) teaching at the elementary school level is very likely to intersect with Natural Science Learning (IPA). Especially for now, with the 2013 curriculum, learning through thematic learning is a combination of teaching between one subject and another. In this research method used descriptive qualitative research methods with several types of formality. This study aims to determine the integration of social studies and science learning in class IV and how teachers integrate social studies learning in science learning and see the supporting factors and obstacles in the process of integrating social studies and science learning in students, especially class IV MI P2A. Meri, Kutasari, Purbalingga.This research is based on the lack of mastery of social studies and science learning in class IV MI P2A Meri. The result of this research is that educators strive to master social science and science material so that the fourth grade students 'social studies and science scores increase because the level of students' understanding of the integration of social studies and science learning By carrying out various programs, including implemented by the head of madrasah towards educators, by educators towards students. A suitable approach to teaching is story and dialogue, because with various approaches students will be encouraged while outside the classroom carried out through several programs including intracurricular and extracurricular activities. Integrated and connected social studies and science learning can provide additional knowledge to students. Mainly the integration of social studies learning which is teaching at the selected social level with social science rules that are used for the purpose of the teaching process. Likewise, science learning also leads to the development of the affective aspects of students from an early age in dealing with life in the natural environment.
\end{abstract}

Keywords: Integration, social studies learning, science learning, class IV MI P2A Meri

\begin{abstract}
Abstrak. Integrasi pengajaran Ilmu Sosial (IPS) di tingkat sekolah dasar sangat mungkin bersinggungan dengan Pembelajaran Ilmu Pengetahuan Alam (IPA). Apalagi untuk saat ini dengan kurikulum 2013 pembelajaran melalui pembelajaran tematik yang merupakan perpaduan pengajaran antar mata pelajaran satu dengan mata pelajaran lainnya. Pada metode penelitian ini dipakai metode penelitian kualitatif deskriptif dengan beberapa jenis formalitas. Penelitian ini bertujuan untuk mengetahui keterpaduan pembelajaran IPS dan IPA di Kelas IV dan bagaimana guru mengintegrasikan pembelajaran IPS dalam pembelajaran IPA serta melihat faktor penunjang dan rintangan dalam proses integrasi pembelajaran IPS dan IPA pada siswa, khususnya Kelas IV MI P2A. Meri, Kutasari, Purbalingga.Penelitian ini dilandasi oleh minimnya penguasaan pembelajaran IPS dan IPA siswa kelas IV MI P2A Meri. Hasil dari penelitian ini adalah pendidik mengupayakan penguasaan materi IPS dan IPA agar nilai IPS dan IPA siswa kelas IV meningkat karena tingkat pemahaman siswa terhadap keterpaduan pembelajaran IPS dan IPA. Dengan melaksanakan berbagai program, di antaranya dilaksanakan oleh kepala madrasah terhadap pendidik, oleh pendidik terhadap siswa. Pendekatan yang cocok terhadap pengajaran adalah cerita dan dialog, sebab dengan berbagai pendekatan peserta didik akan terdorong sedangkan di luar kelas dilaksanakan melalui beberapa program diantaranya kegiatan intrakurikuler dan ekstrakurikuler. Pembelajaran IPS dan IPA secara terintegrasi dan terhubung dapat memberikan tambahan pengetahuan kepada siswa.Utamanya integrasi pembelajaran IPS yang adalah pengajaran pada jenjang kemasyarakatan yang dipilih dengan aturan ilmu kemasyarakatan yang dipakai untuk tujuan proses mengajar. Demikian juga dengan Pembelajaran IPA juga mengarah pada pengembangan aspek afektif peserta didik sejak usia dini dalam menghadapi kehidupan di lingkungan alam..
\end{abstract}

Kata kunci: Integrasi, pembelajaran IPS, pembelajaran sains, kelas IV MI P2A Meri.

\section{PENDAHULUAN}

Tujuan pendidikan di Indonesia sering mengalami perubahan disesuaikan dengan kemajuan zaman. Dalam UU Nomor 20 Tahun 2003 menjelaskan bahwa Pendidikan Nasional memiiliki fungsi memajukan kompetensi mencetak sikap serta kultur bangsa yang memiliki martabat dalam rangka mengusahakan kehidupan bangsa (Depdiknas, 2003: 5).("UU 20 Tahun 2003 tentang Sistem Pendidikan 
Nasional | Jogloabang" t.t.) Tujuan dan fungsi pendidikan tersebut tidak akan terbentuk tanpa adanya pengertian yang secara menyeluruh dari materi yang satu terhadap materi lainnya.

Sejak November 2012 Kementerian Pendidikan dan Kebudayaan sudah memobilisasi rancangan formal Kurikulum 2013 (Kurtilas) untuk menggantikan Kurikulum Tingkat Satuan Pendidikan (KTSP) sehingga jenjang pendidikan Madrasah Ibtidaiyah (MI) terdapat beberapa revisi global kandungan kurikulum dimana MI akan menerapkan prosedur pengajaran mendasar tematik terpadu. Kurtilas mengecilkan jumlah mata pelajaran MI dari 10 diringkas ke 6 mata pelajaran, yaitu : Matematika, Bahasa Indonesia, Agama, Penjas Orkes, PPKN serta SBdP.

Dengan diterapkannya kurtilas, bukan berarti bidang studi IPS dan IPA dihilangkan karena substansi dari kedua mata pelajaran tersebut akan dijadikan pembahasan pada seluruh mata pelajaran. Indikator IPS dan IPA mulai tampak di kelas IV sampai VI, tetapi proses pengajaran tetap secara tema integrasi. Ini sesuai dengan anjuran yang diambil oleh penguasa pada saat uji khalayak terhadap perombakan kurtilas di ujung tahun 2012 contohnya, ketika pembahasan sungai di Bahasa Indonesia, pada IPA termasuk pembahasan soal musim penghujan, tempat tinggal dan sebagainya. Sedangkan pada IPS tercakup dalam kemanfaatan sungai bagi masyarakat, serta pentingnya menjaga lingkungan dan sekitarnya.(Muspiroh 2016)

IPS (social studies) hakikatnya tidaklah merupakan sebuah disiplin ilmu, tapi dapat disebut ringkasan dari beberapa disiplin ilmu kemasyarakatan (sosial sciences) untuk dipadukan melalui persoalan-persoalan kemasyarakatan dan disampaikan di Madrasah Ibtidaiyah serta tingkat menengah. IPS dengan beberapa ilmu kemasyarakatan tidak bisa dipilahkan sebab IPS mengarah kepada beberapa ilmu kemasyarakatan pada pelaksanaannya dalam bentuk dan cara, pengertian atau konsepnya. Tidak seluruh ilmu kemasyarakatan bisa dipaparkan pada lingkup IPS, namun dipadankan dengan kekurangan IPS pada teknik pengajarannya di sekolah. Ini ini artinya bagian kupasan IPS lebih sempit dari ilmu-ilmu kemasyarakatan.

IPS juga dikatakan sebagai disiplin yang berkarakter tematik terpadu atau di integrasi pada berbagai bidang ilmu, jadi IPS disebut sebagai studi yang terdiri dari banyak ilmu (multidisipliner). IPS mengaitkan berbagai materi dari beberapa ilmu seperti ekonomi, geografi, sosiologi, sejarah, PPKN, antropologi dan ilmu-ilmu kemasyarakatan lainnya. IPS disatukan guna menelaah tandatanda kemasyarakatan yang timbul di masyarakat secara menyeluruh. ("Diktat+kuliah+-KONSEP+DASAR+IPS.pdf" t.t.)

Proses pengajaran IPS di MI harus mengukur keperluan siswa yang berumur sekitar 6 -12 tahun. Siswa pada kisaran umur 7 - 11 tahun dari pandangan Piaget (1963) sedang pada taraf perkembangaberkembang dalam daya pikir/akademiknya pada tahapan penerapan yang berbentuk nyata.("ILMUPENGETAHUAN-SOSIAL.pdf" t.t.)

Sedangkan, IPA pada dasarnya mencakup empat pokok bagian ialah: (1) cara: hasrat kemauan mengenal suatu materi, gejala semesta, manusia bernyawa, serta kaitannya kausalitas yang memunculkan kajian terkini untuk bisa diselesaikan dengan cara yang sesuai; IPA bersifat berpikir terbuka; (2) tahap: cara menyelesaikan persoalan dengan cara yang tepat; metode ilmiah mencakup susunan hipotesis, rancangan percobaan, menilai, mengukur, dan pengambilan simpulan; (3) hasil: berupa petunjuk, ide , teori, dan aturan; dan (4) penerapan: praktek penggunaan cara yang sesuai teori IPA pada keseharian. Keempat konsep utama IPA ini mestinya ada pada pelaksanaan pendidikan IPA.

Proses pengajaran IPA selayaknya menerapkan metode discovery, cara proses pengajaran yang mengharuskan pada corak dasar: memakai hipotesa, menyimpulkan, dan menghubungkan/ menyiapkan. Corak dasar ini dapat dijelaskan dengan melaksanakan tahapan hipotesa (pengumpulan bahan), mengamati data, dan mengambil simpulan. Pada pembelajaran IPA, siswa dimotivasi agar menemukan sendiri dan mengubah bentuk keterangan secara menyeluruh, memeriksa 
keterangan terbaru melalui norma-norma lampau ke pemikirannya, dan memperbaikinya apabila norma-norma itu sudah tidak lagi relevan.

Pada tingkat MI, IPS dan IPA dikaji pada kelas atas ialah kelas IV (empat) hingga kelas VI (enam), pada kesempatan ini penulis ingin meneliti integrasi dari IPS dan IPA dengan metode pengkombinasian satu materi dengan materi lainnya guna saling menjelaskan, menganalisa, melengkapi, mengisi, dan mendukung berfokus pada Tema Pembelajaran Kurtilas kelas IV. Tema Kurtilas pada Kelas IV diantaranya : Indahnya Kebersamaan, Selalu Berhemat Energi, Peduli terhadap Makhluk Hidup, Berbagai Pekerjaan, Menghargai Jasa Pahlawan, Indahnya Negeriku, Cita-Citaku, Daerah Tempat Tinggalku serta Makanan Sehat dan Bergizi.("Analisis Kompetensi Matematika Kelas 4 S" t.t.) Tetapi, evaluasinya didasari proses, penekanan pada ranah akademik, sikap dan fisik serta evaluasi test dan penilaian portopolio dan saling mengisi. Melalui cara seperti ini, akan tercipta pemahaman yang lengkap, luas dan jelas bagi siswa dalam menyikapi suatu permasalahan.

Integrasi pembelajaran IPS dengan IPA akan menyatukan materi IPS dengan substansi materi IPA. Seperti dalam pembelajaran di kelas materi kelas IV Semester 1, tema 1(Indahnya Kebersamaan) pada sub topik 3 Pendalaman materi makanan khas Indinesia itu ada banyak macamnya, contoh Soto Medan, Soto Lamongan itu bisa dicontohkan sebagai contoh dari benda cair karena memiliki kuah., dan sebagainya. Itu adalah bentuk contoh keterkaitan antara mata pelajaran IPS pada materi makanan khasnya yang dikaitkan dengan betuk-bentuk benda yang merupakan materi dari mata pelajaran IPA.

$$
\text { Dengan pendekatan integrasi }
$$

pembelajaran IPS dan IPA ini akan menetaskan sumber daya manusia yang memiliki daya fikir dalam kemutahiran bangsa dan negara. Kemajuan pendidikan adalah peningkatan dalam peradaban bangsa. Kurikulum pendidikan, harus dapat menelorkan tenaga yang sesuai dengan tingkat kekurangan era sekarang. Oleh sebab itu, pemerintah sedang berupaya dengan terus mengoreksi dan mengembangkan kurikulum demi terlaksananya tujuan pendidikan bangsa. Sehingga tujuan penelitian ini untuk mendeskripsikan dan menganalisa integrasi pembelajaran IPS dan IPA agar mudah dipahami oleh siswa khususnya Kelas IV.

\section{METODE PENELITIAN}

Dalam penelitian ini digunakan metode penelitian kualitatif deskriptif melalui beberapa jenis prosedur. Dengan menyesuaikan jumlah teori yang dengan jumlah jumlah variabel yang akan diamati, sedangkan dalam penelitian kualtatif yang bersifat menyeluruh, maka jumlah teori yang wajib di miliki peneliti kualitatif dianjurkan lebih banyak sebab harus diseimbangkan dengan fenornena yang ber kembang di lapangan. Peneliti kualitatif harus lebih bersifat profesional dengan penguasaan beberapa teori, dan berwawasan luas sehingga dapat menjadi instrumen penelitian yang baik.

Dan strategi pendekatan yang dipandang cocok untuk penelitian ini adalah pendekatan kualitatif., sebab dalam mendeskripsikan masalahnya penulis fokus terhadap artikel ini yang bersifat deskriptif dan analitis. Menurut Lexy J Moleong metode kualitatif ialah berupa fase-fase penelitian kemasyarakatan guna memperoleh data secara deskriptif yang merupakan kata-kata dan gambar dan bukan angka-angka. (Moleong 2019)

Dalam metode penelitian kualilatif harus dilaksanakan secara kontinu dan peneliti berpartisipasi cukup waktu di lapangan dan secara waspada mencatat seluruh kejadian serta melaksanakan analisis reflektif pada dokumen penemuan di lapangan untuk melaporkan penelitian secara mendetail.

\section{HASIL DAN PEMBAHASAN}

Pada integrasi pembelajaran IPS dan IPA dalam kurtilas pada di MI tampak dalam pemaduan pengajaran IPS dan IPA ke dalam pelajaran lainnya pada suatu tema. Contohnya dalam pembelajaran kelas IV semester 1 pada Tema 2 (Selalu Berhemat Energi). Sub Tema 1 menelaah materi tentang "Sumber Energi" dan akan dilaksanakan sebanyak enam kali penyampaian pengajaran. Dalam penyampaian 
pengajaran I, IPS disajikan bersama pelajaran IPA dan Bahasa Indonesia. Dengan KD IPSnya yaitu Mengidentifikasi karakteristik ruang sumber daya alam dan penggunaannya dengan benar (KI-3). Pada KI-4 melalui dialog dan penyelesaian persoalan, peserta didik bisa mencari penjelasan mengenai sumber daya alam dan penggunaannya dengan benar. Melalui dialog menyelesaiakan persoalan, peserta didik bisa menyampaikan hasil penyelidikan sumber daya alam serta penggunaannya dalam wujud catatan yang tersusun dengan urut .(Meldina dkk. 2020a)

KD pada pembelajaran I dapat dipahami pada Gambar 2 berikut ini !

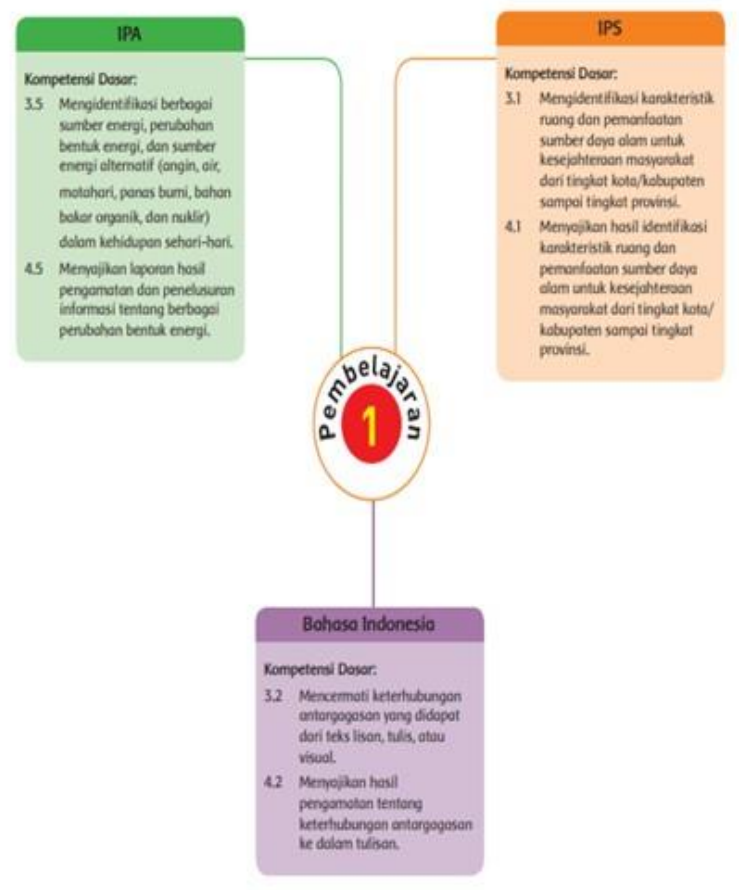

Gambar 2. Pemetaan Kompetensi Dasar Pada Pembelajaran I sub Tema 1 Tema 2

(Isnaeni 2018)

Menurut ulasan di atas terjalin pembelajaran secara kompleks

cara pandang yang melibatkan dua ilmu bahkan bisa lebih. Integrasi multidisipliner ini diterapkan tidak digabungkannya KD di setiap pelajaran, jadi setiap pelajaran mempunyai Kompetensi Dasar sendiri. Sehingga KD IPS masih independen dapat terlihat dengan jelas tidak ber baur menjadi KD baru. Pada setiap tema juga bagian dari topik yang akan diajarkan harus dikaitkan bersama pembelajaran IPS. Pada tiap sub tema diperoleh dengan berbagai langkah pembelajaran.(Meldina dkk. 2020a)

Drake (2007:25)(Setiana 2016) berpendapat bahwa pembelajaran yang mengaitkan kurikulum bersama langkah secara bergantian. Pembelajaran terpadu dapat dilihat dari beberapa segi pandang yang mempunyai keunikan sendiri dalam pengimplementasiannya.

Integrasi antar bidang studi dilaksanakan melalui penggabungan ukuran karakter, pengertian, dan keahlian menjadi kesatuan yang bulat disetiap mata pelajaran. Intergrasi antar bidang studi dilaksanakan dengan mengintegrasika. KD dari berbagai mata pelajaran supaya terhubung satu dan yang lainnya, jadi bisa menguatkan agar terhindar dari tumpuk-menumpuk dan memelihara keserasian pembelajaran.

Pembelajaran di kelas rendah yaitu; kelas 1, 2 dan 3 KD mata Pelajaran IPS dipadukan dalam $\mathrm{KD}$ pelajaran Bahasa Indonesia, dalam KD PPKn, serta dalam Kompetensi Dasar Pelajaran Matematika. Dan pada kelas atas ialah: kelas 4, 5, dan 5) KD dari Pelajaran IPS dipisahkan, Jadi pendekatan terpadunya yaitu dengan menggunakan cara pandang, sedang pembelajarannya tetap memakai tematik terpadu.

Di kelas bawah nama bidang studi IPS dihilangkan, akan tetapi dipadukan. IPS dipadukan dalam KD pelajaran lainnya yaitu B. Indonesia, PPKn, dan Matematika. Sehingga jiwa pembelajaran IPS sebenarnya ada tetapi dipadukan dengan KD pelajaran lain untuk dipadukan dengan kedekatan jiwa. Untuk kelas atas, IPS mempunyai tempat yang sejajar dengan mata pelajaran lainnya. Walaupun pembelajaran dilaksanakan secara terpadu, akan tetapi Kompetensi Dasar bagi IPS tetap dipisahkan dari KD mata pelajaran lain.

Pada kelas bawah keterkaitan penggabungan KD IPS dan IPA di kelas bawah, dilandasi pada keterkaitan arti dan esensi Kemampuan Dasar IPS dan IPA dengan esensi Pendidikan religi dan adab, PPKn, B. Indonesia, Matematika, serta PJOK yang absah bagi kelas I, II, dan III. Namun bagi kelas IV, V dan VI, Kemampuan utama IPS serta IPA bersifat independen dan selanjutnya 
digabungkan pada tema-tema yang tersedia bagi kelas IV, V dan VI. Integrasi pengajaran IPS dan IPA pada Kurtilas di Madrasah Ibtidaiyah sebagai unsur yang penting untuk menggapai tujuan kurikulum pendidikan.(Meldina dkk. 2020b)

IPS dan IPA mempunyai tempat yang sejajar Di antara mata pelajaran lain dan mempunyai hubungan satu dengan yang lain disampaikan secara terpadu. Integrasi berarti memadukan. Pembelajaran integrasi berarti pengajaran yang menyatukan beberapa ranah keilmuan. Pembelajaran integratif juga pembelajaran yang memaduukan kurikulum pada beberapa bentuk penyatuan keahlian, rencana, serta tema lintas keilmuan. Penyatuan ini diterapkan ke dalam dua unsur, ialah integrasi karakter, keahlian dan pengertian pada tahap pengajaran dan penyatuan beberapa teori utama yang berberhubungan.

Pada pengajaran tematik integratif, topik yang ditetapkan berkaitan dengan zona serta kesibukan manusia. Bagi kelas I, II, dan III, dua-duanya memberikan arti yang penting pada mata pelajaran PPKN, Bahasa Indonesia, Matematika, SBdP, serta Penjas Orkes.

Sesuai uraian diatas maka KD dari Ilmu Pengetahuan Sosial dan Ilmu Pengetahuan Alam yang dikelompokkan kedalam mata pelajaran lain mempunyai kedudukan penting dan menjadi pereket dan penunjang Kemampuan utama pada pelajaran lainnya. Secara perspektif koghnitif, siswa belum bisa berfikir tentang kesimpulan dalam menelaah informasi mata pelajaran yang terpecah kecuali kelas IV, V, dan VI sudah mulai nampak memikirkan sesuatu secara abstrak.

Wawasan kepribadian penumbuhan dan Gestalt menyampaikan landasan yang kokoh untuk menggabungkan Kemampuan pokok yang dikelompokkan pada pengajaran tematik. Dilihat dari pandangan transdisciplinarity maka pengelompokan esensi kurikulum secara terpecah ketat tanpa memberi surplus bagi keahlian bermeditasi berikutnya.(Meldina dkk. 2020a).

\section{KESIMPULAN}

Pembelajaran integratif IPS dan IPA merupakan model pendekatan yang sangat penting pada konteks pembelajaran kurikulum 2013. Selaras dengan kenyataan di mana pengajaran terpadu adalah pengajaran yang ditumbuhkan dengan beralas pada teori pengkajian yang dapat dipertanggungjawabkan. Metode pengajaran tterkini IPS sering di ketahui dengan nama metode antar disiplin ilmu.

Proses pemaduan pengajaran IPS bisa dilaksanakan melalui beberapa acuan. Di antara acuan model yang dipakai pada kedudukan kurikulum ini semata-mata dilaksanakan dengan teliti, melalui tahapan persiapan dan aktualisasi. Fase persiapan mencakup Menggambarkan KD, penumbuhan terkait topik, pada penyusunan silabus, dan pada Pembuatan RPP. Langkah penerapan pengajaran dilaksanakan dengan tahap invitas, apersepsi, eksplorasi, mengusulkan penjelasan dalam mengambil kuliah.

Pembelajaran IPS dan IPA di Madrasah Ibtidaiyah berbasis integrassi sangatlah penting karena dengan pengembangan pembelajaran terintegrasi tersebut siswa semakin memahami dan bangkit kepada drinya. dan akan adanya keabsahan aturan-aturan alam dan faktafakta dari ilmu sosial dan ilmu alam yang dipelajari.

Pembelajaran integrasi merupakan pendekatan penting dan perlu dikembangkan terutama dalam pembelajaran IPS dan IPA sebagai model pembelajaran terpadu pada mata pelajaran IPS kerap disebut sebagai pendekatan interdisipliner.("DAFTAR TEMA KURIKULUM 2013 SD/MI LENGKAP INTEGRASI INTRADISIPLINER, INTERDISIPLINER, MULTIDISIPLINER, DAN TRANSDISIPLINER" t.t.)

Pembelajaran terpadu adalah suatu pengaturan yang mengijinkan siswa dengan cara individu ataupun berkelompok tangkas dalam mencari, menggali, dan menjumpai teori dan asas-asas dengan menyeluruh dan lengkap/komplit. Pembelajaran IPA dan IPS pada Madrasah Ibtidaiyah (MI) berbasis integrasi interkoneksi penting sekali. Dengan pengembangan pembelajaran tersebut akan membuat siswa bersemangat untuk bangkit 
kepada dirinya ada prinsip keabsahan aturanaturan semesta.

Melalui pemaduan pada pembelajaran, harkat kemasyarakatan yang dirasakan oleh siswa tidak hanya berpangkal pada latar belakang kemasyarakatannya saja, namun dari harkat kemasyarakatan yang mempunyai pegangan pada lingkungan alam sekitar.(Makmun 2016).

\section{SARAN}

Berdasarkan

kesimpulan

pengaplikasian diatas, maka peneliti mengajukan saran sebagai berikut :

1. Kepala Sekolah

Selalu memantau pengintegrasian pengajaran Ilmu Sosial (IPS) di tingkat sekolah dasar sangat mungkin bersinggungan dengan Pembelajaran Ilmu Pengetahuan Alam (IPA).

2. Guru

Harus selalu kreatif dalam mengembakan perangkat pembelajaran dan pengajaran IPS dan IPA agar siswa tertarik mengikuti pelajaran.

\section{UCAPAN TERIMA KASIH}

Terimakasih untuk semua pihak yang telah membantu terselesaikannya artikel ini terutama untuk Kaprodi Ibunda Hj. Tutuk Ningsih.

\section{DAFTAR PUSTAKA}

"Perspektif_dan_Tujuan_IPS.pdf." t.t. Diakses 25 April 2021. http://file.upi.edu/Direktori/FPIPS/M K_D_U/196209261989041RIDWAN_EFFENDI/Perspektif_dan_ Tujuan_IPS.pdf.

222455-kedudukan-ilmu-pengetahuan-sosialips-pa.pdf." t.t. Diakses 25 April 2021. https://media.neliti.com/media/publicat ions/222455-kedudukan-ilmupengetahuan-sosial-ips-pa.pdf.

7+ Pengertian Ilmu Pengetahuan Sosial (IPS) menurut Para Ahli." t.t. RANGKUMAN PUSTAKA (blog). Diakses 4 April 2021. http://www.rangkumanpustaka.com/20 17/05/7-pengertian-ilmu-pengetahuansosial.html.
Analisis Kompetensi Matematika Kelas 4 S.” t.t. Diakses $28 \quad$ April 2021. https://123dok.com/document/zkkmmk $\underline{\text { zz-analisis-kompetensi-matematika- }}$ kelas-s.html.

BAB I.pdf." t.t. Diakses 25 April 2021. http://eprints.ums.ac.id/39320/4/BAB\% 20I.pdf.

BAB II.pdf." t.t. Diakses 17 April 2021. https://eprints.uny.ac.id/48936/3/BAB \%20II.pdf.

DAFTAR TEMA KURIKULUM 2013 SD/MI LENGKAP - $\quad$ INTEGRASI INTRADISIPLINER, INTERDISIPLINER, MULTIDISIPLINER, DAN TRANSDISIPLINER." t.t. Diakses 25 April 2021. http://indeksprestasi.blogspot.com/201 4/11/daftar-tema-kurikulum-2013sdmi-lengkap.html.

Diktat+kuliah+-+KONSEP+DASAR+IPS.pdf." t.t. Diakses 27 April 2021. http://staffnew.uny.ac.id/upload/13178 5898/pendidikan/Diktat+kuliah++KONSEP+DASAR+IPS.pdf.

ILMU-PENGETAHUAN-SOSIAL.pdf." t.t. Diakses $27 \quad$ April 2021. https://www.usd.ac.id/fakultas/pendidi kan/f113/PLPG2017/Download/materi/ SD/ILMU-PENGETAHUANSOSIAL.pdf.

Isnaeni, MUhamad. 2018. Selalu Berhemat Energi (Tema 2). Buku Siswa Kelas IV SD/MI

Makmun, H. A. Rodli. 2016. "PEMBENTUKAN KARAKTER BERBASIS PENDIDIKAN PESANTREN: Studi di Pondok Pesantren Tradisional dan Modern di Kabupaten Ponorogo." Cendekia: Jurnal Kependidikan dan Kemasyarakatan 12 (2): 211-38. https://doi.org/10.21154/cendekia.v12i 2.226.

Meldina, Tika, Melinedri Melinedri, Alfiana Agustin, dan Siti Hadijah Harahap. 2020b. "Integrasi Pembelajaran IPS pada Kurikulum 2013 di Sekolah Dasar." AR-RIAYAH : Jurnal 
Terakreditasi Peringkat 4 (No. SK: 36/E/KPT/2019)

Pendidikan Dasar 4 (1): 15-26. https://doi.org/10.29240/jpd.v4i1.1572.

Meldina, Tika, Melinedri Melinedri, Alfiana Agustin, dan Siti Harahap. 2020a. "Integrasi Pembelajaran IPS pada Kurikulum 2013 di Sekolah Dasar." AR-RIAYAH : Jurnal Pendidikan Dasar 4 (Juni): 15. https://doi.org/10.29240/jpd.v4i1.1572.

Moleong, Lexy J. 2019. Metodologi Penelitian Kualitatif. Edisi Revisi. Bandung: PT Remaja Rosdakarya.

Muspiroh, Novianti. 2016. "PEMBELAJARAN TEMATIK INTEGRATIF IPA DAN IPS DI MADRASAH IBTIDAIYAH (MI) DALAM KURIKULUM 2013." Cendekia: Jurnal Kependidikan dan Kemasyarakatan 14 (Juli): 75 . https://doi.org/10.21154/cendekia.v14i 1.548 .

Pengertian ips menurut para ahli dan daftar pustakanya - Penelusuran Google.” t.t. Diakses 4 April 2021. https://www.google.com/search?q=pen gertian+ips+menurut+para+ahli+dan + d aftar+pustakanya\&oq=\&aqs=chrome. 0 . 69i59i45018.5368575j0j7\&sourceid=ch rome\&ie=UTF-8.

Prasetyo, Sigit. t.t. "OPTIMALISASI PENGGUNAAN KIT IPA DALAM PEMBELAJARAN IPA DI SEKOLAH DASAR (SD)" 3 (1): 20.

Setiana, Nana. 2016. "Pembelajaran IPS Terintegrasi dalam Konteks Kurikulum 2013." EduHumaniora | Jurnal Pendidikan Dasar Kampus Cibiru 6 (2). https://doi.org/10.17509/eh.v6i2.4574.

UU 20 Tahun 2003 tentang Sistem Pendidikan Nasional | Jogloabang." t.t. Diakses 25 April 2021. https://www.jogloabang.com/pustaka/u u-20-2003-sistem-pendidikan-nasional. 